\begin{tabular}{|c|c|c|}
\hline \multirow{3}{*}{$\begin{array}{r}\text { Case Reports in } \\
\text { Gastroenterology }\end{array}$} & \multirow{2}{*}{\multicolumn{2}{|c|}{ Case Rep Gastroenterol 2016;10:679-684 }} \\
\hline & & \\
\hline & $\begin{array}{l}\text { DOI: 10.1159/000452205 } \\
\text { Publisned online: November 14, } 2016\end{array}$ & $\begin{array}{l}\text { (c) } 2016 \text { The Author(s) } \\
\text { Published by S. Karger AG, Basel } \\
\text { www.karger.com/crg }\end{array}$ \\
\hline & \multicolumn{2}{|c|}{$\begin{array}{l}\text { This article is licensed under the Creative Commons Attribution-NonCommercial } 4.0 \\
\text { International License (CC BY-NC) (http://www.karger.com/Services/OpenAccessLicense). } \\
\text { Usage and distribution for commercial purposes requires written permission. }\end{array}$} \\
\hline
\end{tabular}

\title{
Endoscopic Removal of a Duodenal-Perforating Leg of Glasses with Dormia Basket
}

\author{
Li Wang $^{\mathrm{a}}$ Wei Wen ${ }^{\mathrm{a}}$ Jiamiao Huang ${ }^{\mathrm{a}}$ Weijie Hu $\mathrm{Hu}^{\mathrm{a}}$ Renrong Zhou ${ }^{\mathrm{a}}$ \\ Xin $\mathrm{Li}^{\mathrm{a}}$ Xiaojiang Wang ${ }^{\mathrm{b}}$ \\ ${ }^{a}$ Department of Gastroenterology, the Affiliated 81st Hospital of Nanjing University of \\ Chinese Medicine, Nanjing, China; ${ }^{b}$ Department of Anesthesiology, the Affiliated 81st \\ Hospital of Nanjing University of Chinese Medicine, Nanjing, China
}

\section{Keywords}

Foreign body · Duodenal perforation · Endoscopic removal

\begin{abstract}
Ingestion of foreign bodies is common in clinical practice. Most ingested foreign bodies will pass through the gastrointestinal (GI) tract without any problems. While GI tract injury due to the ingested foreign body such as a toothpick, a fishbone, a date pit, or a chicken bone, is common, duodenal perforation is rare. In this report, our experience with this rare entity is shared. We present a 38-year-old male patient with GI tract perforation in the bulbus of the duodenum due to a leg of glasses. The patient was admitted to our hospital with severe abdominal pain. Right upper quadrant tenderness was detected at physical examination, and leukocytosis on the laboratory test results. Plain X-ray and computerized tomography showed an ingested foreign body in the bulbus of the duodenum. A leg of glasses perforating the duodenum was removed with endoscopy. The patient was managed nonoperatively, and discharged without any complications on the eighth day after endoscopy. Endoscopic removal and nonoperative management may be feasible in carefully selected patients with duodenal-perforating foreign bodies.

(C) 2016 The Author(s)

Published by S. Karger AG, Basel
\end{abstract}

KARGER

Department of Gastroenterology

The Affiliated 81st Hospital of Nanjing University of Chinese Medicine

Jiangsu Province, Nanjing (China)

E-Mail mailxiaoyuang@163.com 
Wang et al.: Endoscopic Removal of a Duodenal-Perforating Leg of Glasses with Dormia Basket

\section{Introduction}

Foreign bodies ingestion is a common clinical emergency, most of them leave the gastrointestinal (GI) tract spontaneously, but $10-20 \%$ of ingestions of foreign bodies require endoscopic removal and less than $1 \%$ require surgery $[1,2]$. Foreign bodies ingestion is a common disease in clinical presentations, which can be either acute or chronic. The most frequently encountered types are needles, coins, batteries, food, various sharp objects, bone fragments, cartilages, pieces of plastic, glass, etc. It has been reported that foreign body perforations of the GI tract most frequently occurs at regions of acute angulation and their thicker mucosal walls such as the duodenum or the ileocecum and the rectosigmoid $[3,4]$.

GI perforation may present as only odynophagia or abdominal pain. If the injury is not witnessed, a definite preoperative diagnosis is uncertain and clinical intervention may be delayed because symptoms are nonspecific. Diagnostic imaging (X-ray, CT, MRI) could identify the location, shape, size, and number of foreign body and contribute to establish the effective therapeutic approach [5].

The technology of gastric foreign body extraction under endoscope is already very mature, but a foreign body extraction with a length of $>5 \mathrm{~cm}$ under endoscope often results in serious complications such as perforation or GI bleeding.

Here, we report a successful case of endoscopic removal of a leg of glasses of $12.5 \mathrm{~cm}$ length from the stomach which was perforating the duodenum.

\section{Case Presentation}

A 38-year-old male patient, presented in our clinic with severe abdominal pain. The only symptom reported by the patient was right low abdominal pain that appeared 10 days before. He had rebound tenderness located at the right abdominal quadrant without vomiting blood and black stool. His past medical history was positive for appendectomy.

Laboratory tests revealed raised inflammatory markers (ESR $50 \mathrm{~mm} / \mathrm{h}$, WBC 11,300/ $\mathrm{mm}^{3}$ ) with no other main abnormalities. Electrocardiography was normal and the myocardial injury was excluded. Plain X-ray showed right upper pulmonary nodules with a slightly higher-density shadow that might represent a foreign body. Standing X-ray films showed a metal shadow in the right abdominal quadrant between the third lumbar vertebra to the fifth lumbar vertebra (Fig. 1). A linear hyperdense foreign body penetrating the entire bowel wall at the duodenum and two limitations of emphysema, lung pulmonary lesions, highdensity shadow around the hepatic portal vein and shadow around the local end were detected on the abdominal computerized tomography (CT) scan (Fig. 2). Considering foreign body ingestion, his history was re-questioned, and the patient remembered that he had swallowed a leg of glasses 6 months ago. With upper GI endoscopy, the diagnosis was confirmed that a long foreign body (a leg of glasses) was lodged in the bulbus of the duodenum with purulent secretions surrounding the foreign body, the descending part of mucosa was normal. Since the perforation area was pinpoint small and there was little free air detected by the CT scan, a decision to attempt nonoperative management was made. Dormia basket was applied to pull the foreign body, followed by carefully withdrawing it back into the stomach. Titanium clips were successfully used to close the duodenal perforation through purse string suture, and the leg of glasses was subsequently removed out. Finally, we implanted a threecavity nutrient tube into the jejunum of the patient (Fig. 3a, b). The endoscopy operative course was smooth and uneventful. Enteral nutrition and broad-spectrum antibiotics were 
administrated for 1 week, and oral diet was started after rebound tenderness disappeared. Then, the patient was discharged without any complications and in good clinical conditions on the eighth day after endoscopy with normal blood biochemical examination (ESR 10 $\mathrm{mm} / \mathrm{h}, \mathrm{WBC} 5,600 / \mathrm{mm}^{3}$ ).

\section{Discussion}

Endoscopists often encounter cases of foreign bodies in the GI tract. It is especially necessary to confirm the foreign body's shape, size, number and nature of material [3]. In general, slender, long, sharp-ended objects are more likely to lodge in the GI tract and causing perforation than objects of other shapes. In this case, the leg of glasses which is slender and long was swallowed by the male patient and lodged in the entire bowel wall at the duodenum and caused perforation finally.

In cases of foreign bodies in the GI tract, treatments are chosen according to object type and location [6]. The equipment must include a complete kit for flexible and rigid endoscopy, and auxiliary equipment that includes crocodile teeth type forceps or mouse, polypectomy loops with or without a pannier, polyp extractors, Dormia type panniers, etc. [7]. Flexible endoscopic technique is considered the first choice, especially for single foreign bodies with distal impaction site [8]. In this case, the leg of glasses was a long metallic object, prone to slipping and difficult to grasp. The Dormia basket we used was easily maneuvered into position, and the foreign bodies could easily be grasped within the basket wires. In our experience, we feel that the basket offers a greater degree of rotational capabilities and a wider diameter to grasp the foreign object, without further injury. Plain X-ray is simple and useful in the diagnosis of ingested metal foreign body. Abdominal CT may be helpful in patients with peritoneal irritation findings [9].

Since the suspicion or patient history will lead an initial diagnosis of foreign body ingestion, the majority of them may be managed nonoperatively. It is very important to ask for details of the patient history [10]. The history of the patient was re-questioned when the Xray and CT scan found that there was a foreign body penetrating the entire bowel wall at the duodenum. Endoscopy is the first choice for the removal of the foreign object in upper GI. Endoscopic removal may be possible in up to $10 \%$ of the cases [11]. Surgical exploration may be necessary when the clinical course of the patient deteriorates or when there is a foreign object within the abscess $[10,11]$.

\section{Conclusions}

In this case, we successfully diagnosed and treated a male patient with removal of a duodenal-perforating leg of glasses by endoscopy. In conclusion, when a patient was admitted with abdominal pain, foreign body ingestion and possible GI perforation should be considered. The detailed medical history should be obtained. Plain X-ray and abdominal CT scan are helpful in detecting the localization of foreign body and perforation. A Dormia basket can be utilized for the removal of ingested foreign bodies in the upper GI tract. 
Wang et al.: Endoscopic Removal of a Duodenal-Perforating Leg of Glasses with Dormia Basket

\section{Statement of Ethics}

The authors have no ethical conflicts to disclose.

\section{Disclosure Statement}

The authors declare that there are no conflicts of interest regarding the publication of this article.

\section{References}

1 Boškoski I, Tringali A, Landi R, Familiari P, Contini ACI, Pintus C, et al: Endoscopic retrieval of a duodenal perforating teaspoon. World J Gastrointest Endosc 2013;5:186.

2 Webb WA: Management of foreign bodies of the upper gastrointestinal tract. Gastroenterology 1988;94:204-216.

-3 Chaves DM, Ishioka S, Félix VN, et al: Removal of a foreign body from the upper gastrointestinal tract with a flexible endoscope: a prospective study. Endoscopy 2004;36:887-892.

4 Birk M, Bauerfeind P, Deprez PH, et al: Removal of foreign bodies in the upper gastrointestinal tract in adults: European Society of Gastrointestinal Endoscopy (ESGE) Clinical Guideline. Endoscopy 2016;48:489-496.

-5 Goh BK, Chow PK, Quah HM, Ong HS, Eu KW, Ooi LL, et al: Perforation of the gastrointestinal tract secondary to ingestion of foreign bodies. World J Surg 2006;30:372-377.

-6 Chung YS, Chung YW, Moon SY, et al: Toothpick impaction with sigmoid colon pseudodiverticulum formation successfully treated with colonoscopy. World J Gastroenterol 2008;14:948-950.

7 ASGE Standards of Practice Committee; Ikenberry OS, Jue TL, Anderson MA, Appalaneni V, Banerjee S, Ben-Menachem T, et al: Management of ingested foreign bodies and food impactions. Gastrointest Endosc 2011;73:1085-1091.

-8 Bounds BC: Endoscopic retrieval devices. Tech Gastrointest Endosc 2006;8:16-21.

-9 Predescu D, Predescu I, Sarafoleanu C, Constantinoiu S: Oesophageal foreign bodies -from diagnostic challenge to therapeutic dilemma. Chirurgia (Bucur) 2016;111:102-114.

$\checkmark 10$ Chen C, Su Y, Lai Y, et al: Fish bone-related intra-abdominal abscess in an elderly patient. Int J Infect Dis 2010;14:e171-e172.

11 Tumay V, Guner OS, Meric M, et al: Endoscopic removal of duodenal perforating fishbone - a case report. Chirurgia (Bucur) 2015;110:471-473.

12 Sugawa C, Ono H, Taleb M, Lucas CE: Endoscopic management of foreign bodies in the upper gastrointestinal tract: a review. World J Gastrointest Endosc 2014;6:475-481. 


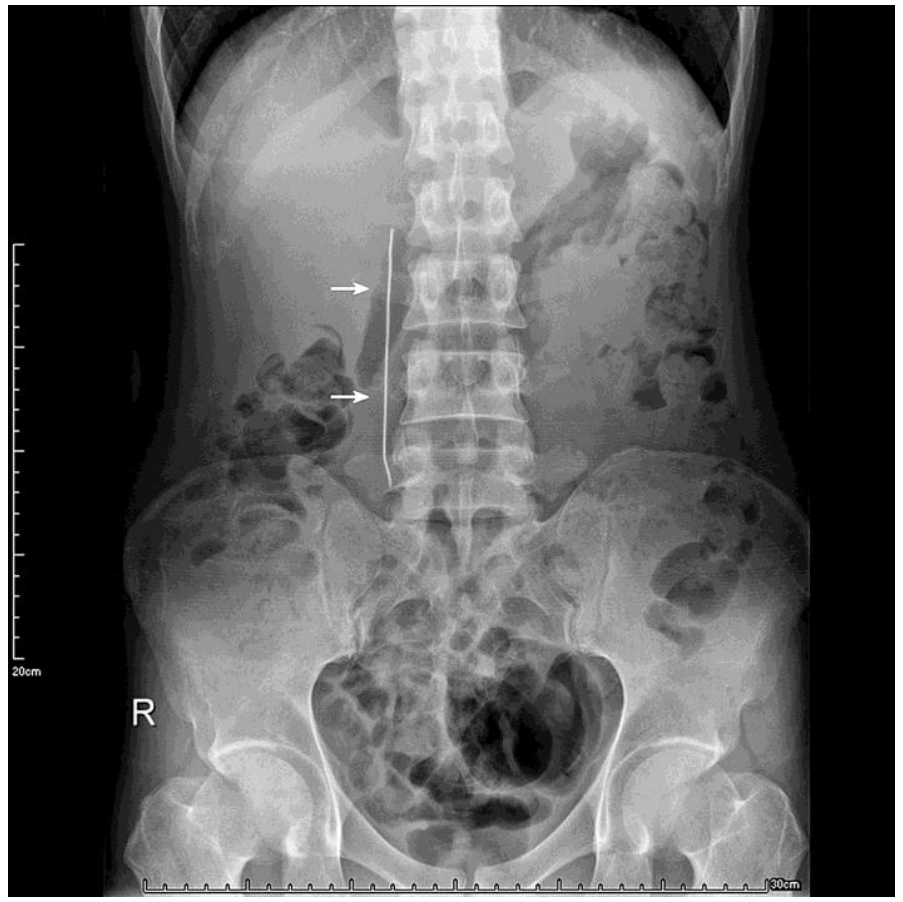

Fig. 1. Standing X-ray films showed a metal shadow in the right abdominal quadrant between the third lumbar vertebra and the fifth lumbar vertebra level.

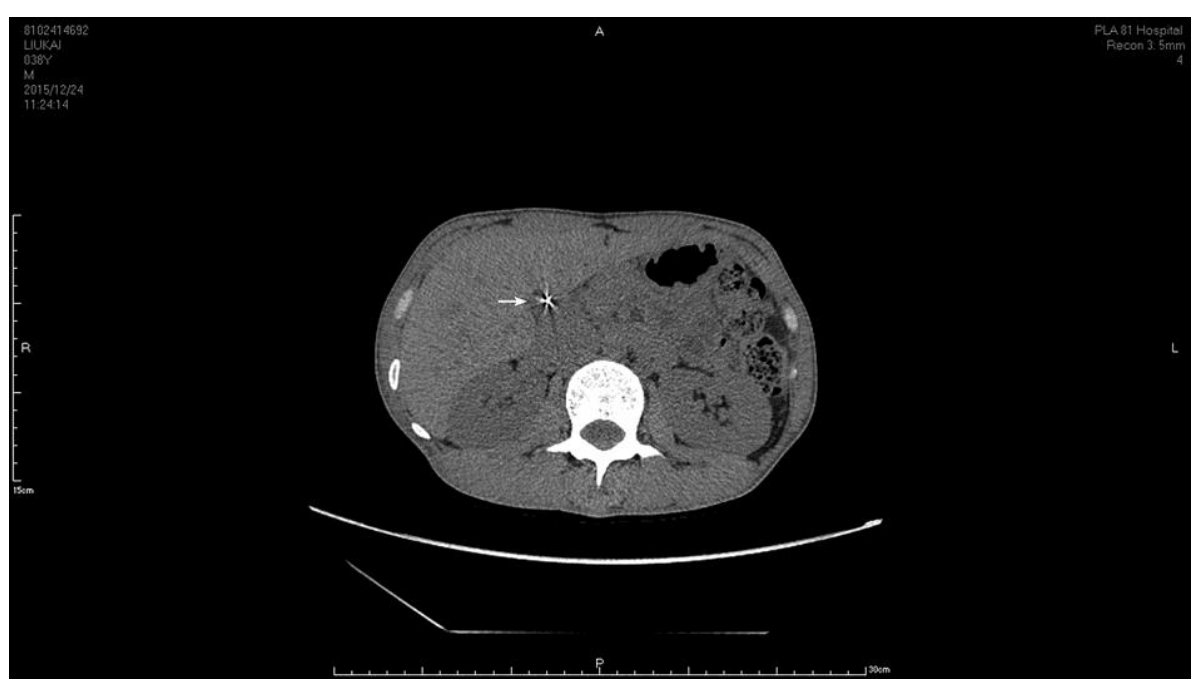

Fig. 2. CT findings: a linear hyperdense foreign body penetrating the entire bowel wall at the duodenum. 

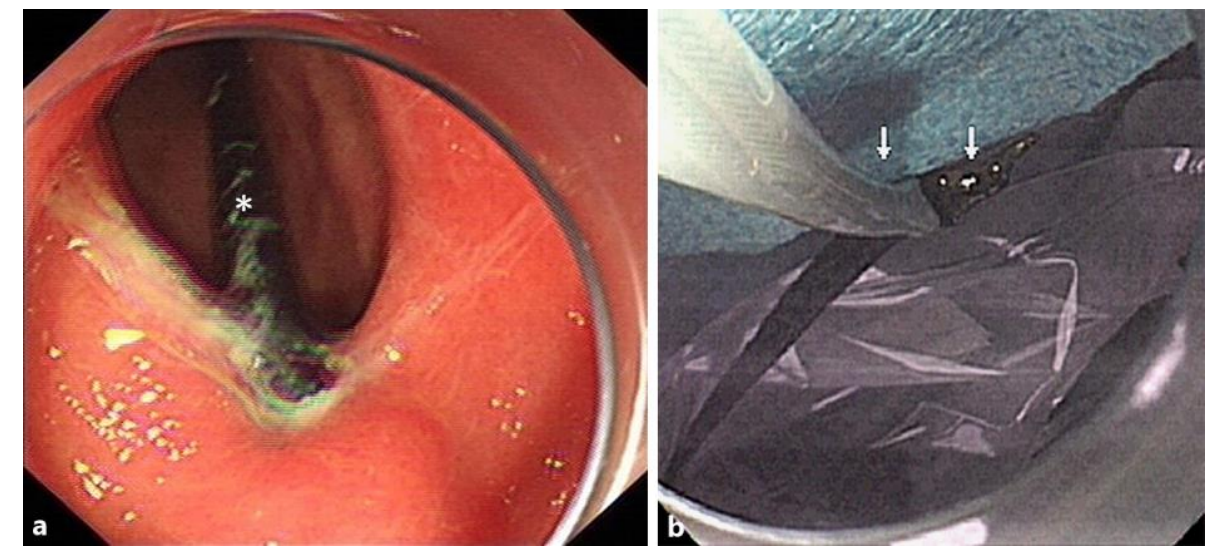

Fig. 3. a Endoscopic image showing a black foreign body lodged in the bulbus of the duodenum and purulent secretions surrounding the foreign body. $\mathbf{b}$ A leg of glasses after its removal. 